\title{
An Empirical Study on Momentum and Contrarian Effects in Chinese Futures Market*
}

\author{
Qing Xue, Zhen Wang \\ China University of Petroleum, Beijing, China \\ Yang Li \\ North Industries Group Finance Company Ltd., Beijing, China
}

\begin{abstract}
As Chinese futures market is on track of standardized development, its efficiency and related investors' strategy have drawn wide attention from scholars worldwide. This paper aims to provide an empirical study on momentum and contrarian effects in Chinese futures market. It investigates how efficient this market has been after decades of development and what investment strategy can be used to obtain significant positive excess return. The analysis is based on weekly and monthly trading data of the major commodity futures listed in three Chinese futures exchanges since January, 1999. By establishing a zero-cost investment trading strategy as testing method, this empirical study shows that contrarian effect is significant in both weekly frequency (short term) and monthly frequency (long term), and that as the holding period extends, the contrarian effect disappears. It also concludes that the reverse effects in the short term and long term origin from three factors: defective information transfer system, mean reversion in the contrarian effect, and immaturity of investors' mentality.
\end{abstract}

Keywords: Chinese futures market, momentum and contrarian effects, market over-reaction, market under-reaction

\section{Introduction}

According to the theory of limited arbitrage, factors such as flawed market system, irrationality of investors, defective incentive, and control mechanism will restrict the arbitrage behaviors of arbitragers, who, as a consequence, are unable to correct the deviation of the market price. This theory explains why the market would become inefficient under the disturbance of noise trader and why the abnormalities of over-reaction and under-reaction would emerge on the capital market. Furthermore, it supports the effectiveness of the momentum and contrarian strategies in the capital market investment.

Typically as an emerging capital market, Chinese futures market is sharply different from the mature ones in the US or Europe. Therefore, features of Chinese futures market, particularly the aspects concerning the

\footnotetext{
*Acknowledgements: The authors gratefully acknowledge the financial support provided by the Ministry of Science and Technology of China under the name of its soft science research projects "Research on the Roles Played by Fossil Energy during the Global Energy Transformation” (No. 2013GXS3B049) and the National Science and Technology Key Project (No.2011ZX05030).

Qing Xue, Ph.D. candidate from School of Business Administration, China University of Petroleum (Beijing), China.

Zhen Wang, professor from Academy of Chinese Energy Strategy, China University of Petroleum (Beijing), China.

Yang Li, M.A. Econ., North Industries Group Finance Company Ltd, Beijing, China.

Correspondence concerning this article should be addressed to Zhen Wang, No.18 Fuxue Rd., Changping District, Beijing, China (102249). E-mail: wangzhen@cup.edu.cn.
} 
investors' behavior, shall be considered when applying momentum and contrarian strategies to the analysis of its investors' behavior. Main features of Chinese futures market can be summarized as follows:

(1) With the absence of extensive institutional investors, the market consists of medium and small investors. As a result, investment usually falls into noise trade, during which blindness and the phenomenon of irrational bias are rather pronounced. Other phenomena include representative bias, conservatism bias, and over-confidence.

(2) The market features high turnover rate or high trade frequency. For instance, from January, 2005 to December, 2011, the weekly turnover of copper and soybean futures average 33,022 and 27,013 hands respectively. This can be attributed to the lack of knowledge of futures investment among Chinese investors. Losing sight of high potential risks, they believe that the futures market enjoys lower costs and greater chances for profit compared with stock market. As a consequence, massive investors and their funds swarm into the futures market, leading to a high turnover rate, which is inclined to cause price over-reaction rather than under-reaction.

(3) Since Chinese futures companies are less mature than those in the US or Europe, competitions among them concerning brokerage and settlement function mainly center on agent service. In China, futures companies feature large number but small scale. Due to low quality, these companies often fail to provide timely and effective market information, thus the suggestions or analysis reports they provide may end up misleading their investors. This might further aggravate market over-reaction.

To sum up, as Chinese futures market remains an emerging one, investors share different qualities from their counterparts in the mature markets, its activities mainly belong to noise trade. Therefore, an empirical study should be conducted to verify the existence of market over-reaction and analyze the main source of these excess returns. This study will contribute to comprehending the development status of Chinese futures market and providing investment strategies for potential investors. To investigate the momentum and contrarian effects in Chinese futures market, this paper develops as followed: After the introduction, the second section will provide a retrospect on the existent studies on the developed futures markets in Europe and North America, as well as developing markets in Asian areas; the third part will describe the research design of zero-cost portfolio. Detailed evidence for the existence of reversal effects in the short run and long run will be observed in the fourth part. The last section is conclusions.

\section{Literature Review}

Fama (1998) defended his market efficiency theory and proved that long-term return reversal is not the norm, but he still left an open puzzle for return anomalies in the short term. Most follow-up studies on the developed stock markets support the existence of short-term reversal. However, there remain some disputes over the existence of short-run reversal in the futures market, as well as the effectiveness of contrarian strategy. In an analysis of 24 types of American futures contracts, Wang (2004) discussed whether weekly return rate of the future contract will yield excess return, through the adoption of momentum or contrarian strategies proposed by Lo and Mackinlay (1990). Its results indicate that contrarian strategy will lead to profits, and as is revealed by an in-depth study, these profits derive from over-reaction. Pirrong (2005) studied the existence of momentum effects in the futures market of Asia, Europe, Australia, and other regions apart from the US. This research concludes that momentum effect will occur in the futures market in the middle term (three to nine months) and contrarian effect in the long run (one to two years). It also finds that the performance of 
momentum effect cannot be entirely explained by the CAPM model and Fama-French three-factor mode (Fama \& French, 1992). Pilar, Luis, and Rafael (2005) decided to study the existence of momentum effect in Spanish futures market, since they believe that small market is more likely to remove momentum effect due to restraints on shorting and high transaction cost. According to their findings, it is indeed more likely for momentum strategy to yield abnormal return in the futures market than in the stock market. The abnormal return rate will be no lower than $3.65 \%$ and can still reach $1.58 \%$ when taking into account the cost. Joëlle and Georgios (2007) studied the existence of momentum effect through a survey into 31 kinds of commodity futures in the US. The research finds that momentum effect can lead to significant excess return in short and middle term (one to 12 months). When the ranking and holding period are 12 months and one month respectively, excess return will culminate at $14.6 \%$. Shen, Szakamary, and Sharma (2007) also studied the existence of momentum effect in the American commodity futures and found momentum effect in the short and middle term (one to 12 months), which is similar to the findings concerning the American stock market. In addition, they take a step forwards by exploring the causes of this effect. They adopt the same measure with Jegadeesh and Titman (2001) to investigate whether excess return results from risk compensation or investor's behavior. This study finds that excess return reaches its highest in the 11th month and declines thereafter until approaching $1 \%$ in the 29th month. This result is consistent with the market efficiency prediction that apparent anomalies tend to disappear in the long run (Fama, 1998)

Given the worldwide researches on regional financial markets above, momentum effect plays a part in the investment decision, because it brings about a positive feedback loop, no matter the over-reaction is caused by irrational investors or asymmetric information. However, the climbing over-reaction can be slowed down by high transaction cost or restrictions especially in a less developed market, such as China. With these two interactive forces, it's implausible to reason whether Chinese futures market can remove momentum effect or go the opposite side of contrarian by taking evidence from matured markets like the United States. Although the earliest Chinese commodity exchange has been established for 22 years, regulations were imposed on foreign capital investment except qualified foreign institutional investor (QF II). The administration and launching of new products are currently in progress, for example, China started to establish an international crude oil futures market at the very beginning of 2015, becoming the third such market in the world after the United States and the United Kingdom. So it is worth investigating the efficiency of Chinese futures market.

\section{Portfolio Design for Momentum and Contrarian Effect Testing}

This paper is concerned with the momentum and contrarian strategies proposed by such scholars as De Bondt and Thaler (1985) to test whether contrarian strategy (buying losers and selling winners) yields excess return. A similar yet opposite measure was adopted by Jegadeesh and Titman (1993) to study momentum trade strategy (buying winners and selling losers) of CRSP (Center for Research in Security Prices) from 1965 to 1989. This paper is intended to study the existence of momentum or contrarian effect in Chinese futures market based on momentum method proposed by Jegadeesh and Titman (1993).

To examine whether momentum and contrarian strategies can yield excess return, ranking period must be established in the first place. It will be divided into three categories: short-term ranking period (one, two, four, and eight weeks), middle-term ranking period (one to nine months), and long-term ranking period (18, 24, and 36 months). The best performing $10 \%$ in the ranking period constitutes the winner portfolio, while the worst performing $10 \%$ constitutes the loser portfolio. It can be represented by "Rank $\left(R_{i}(t-k, t)\right), i=1, \ldots, N$ ”, which 
refers to results of cumulative return rate of future $i$ (a total of $N$ kinds) from $t-k$ to $t$, sorted from bottom to top. This study focuses on the portfolio that is formed by selecting two kinds of commodity futures, each from the $10 \%$ group with the best performance and the worst performance.

According to the momentum strategy (buying winners and selling losers) proposed by Jegadeesh and Titman (1993), winner portfolio still shows an upward trend after the ranking period, whereas loser portfolio will face a downward trend, hence buying winners and selling losers. In contrary to momentum strategy, contrarian strategy expects an upward trend for losers after its ranking period, hence buying losers and selling winners, so as to establish zero-cost portfolio. Then it is required to buy and hold the assets for a certain period of time (holding period). In order to examine the existence of momentum or contrarian effect, the holding period herein will also be divided into three categories: short-term holding period (one, two, four, and eight weeks), middle-term holding period (one to nine months), and long-term holding period (18, 24, and 36 months).

\section{Calculation of Single-period Return}

Return rate is calculated based on the logarithm of closing price of two trading months/weeks. There are limited kinds of commodity futures in Chinese futures market and commodity futures that carry strong financial attributes, such as copper and aluminum feature wide fluctuations. As a result, these commodity futures can easily appear in winner or loser portfolio. However, it is difficult for those with narrow fluctuations to be incorporated. Drawing on the method by Pirrong (2005), this study calculates the variance of weekly/monthly return of each commodity futures, adjusts, and standardizes their weekly/month return rate. This standardization process only applies to the returns during ranking period, so that the variance each commodity futures can be adjusted. Therefore, commodity futures can be incorporated in the ranking of winner and loser portfolio in an equal manner. The formula for standardization is

$$
\hat{r}_{i, t, J}=\frac{\bar{r}_{i, t, J}}{\sqrt{\sum_{j=t-J}^{t} N_{i, j} \sigma_{i, j}^{2}}}
$$

in which $\hat{r}_{i, t, J}$ is the standardized return rate of contract $i$ under the ranking period $J$ and period $t, \bar{r}_{i, t, J}$ represents the return rate under the ranking period $J$ and period $t, N_{i, j}$ is the number of trading day of contract $i$ in $j$ month, and $\sigma_{i, j}^{2}$ represents the variance of daily return rate of contract $i$ in $j$ month.

\section{Selection of Portfolio Weight}

In the construction of assets portfolio, two methods can be adopted to select the weight of commodity futures, namely, Equally-Weighted Strategy (ES) and Weighted Relative Strength Strategy (WRSS). ES places equal weight to different futures during the construction of portfolio and based thereupon establishing a winner-loser portfolio. Jegadeesh and Titman (1993) adopt a different method—WRSS for the purpose of "high attention to high return", in other words, attaching high importance to futures with highest excess return. To construct a portfolio, it firstly divides all futures into two groups. Futures with higher return rate than the average in the futures market will be categorized as winner portfolio, while those with lower rate will be loser portfolio. Then it adjusts the investment weight based on the dispersion of individual asset's return rate relative to market average. Hence the investment weight of individual futures commodity can be calculated as

$$
w_{i, t}(j, k)=\frac{1}{N}\left(r_{i, t-k}-r_{m, t-k}\right)
$$


in which $N$ means the number of futures commodity, $w_{i, t}(j, k)$ represents investment weight of commodity $i$ in period $t$ under the ranking period $j$ and holding period $k, r_{i, t-k}$ is the return rate of the individual commodity futures from period $t-k-j$ to $t-k$, and $r_{m, t-k}$ is the average return rate of the futures commodity in the market from period $t-k-j$ to $t-k$. Accordingly, a zero-cost portfolio can be constructed and its return in period $t$ is:

$$
\pi_{t}(j, k)=\sum_{i=1}^{N} w_{i, t}(j, k) r_{i, t}
$$

\section{Time Lag Method}

In the study of momentum and contrarian strategies, a certain period of time lag will generally be introduced after observation period. This is defined as lagged holding period strategy. During the construction of portfolio, time lag mainly aims to avoid microstructure effect in the market (Lo \& MacKinlay, 1990; Jegadeesh \& Titman, 1993, 1995). The impacts of factors, such as bid-ask spread, price pressure, and lagged reaction effect, can be weakened by selecting lagging period. This paper proceeds by selecting a lagging period of one month and one week.

\section{Annualization of Return Rate}

Since strategies are applied to different periods of time, from the perspective of numerical value, returns yielded from short-term momentum and contrarian strategies are smaller than that from long-term strategy. Therefore, an analysis of effect of momentum and contrarian strategies based thereupon will inevitably lead to biased result. To avoid this situation, all returns mentioned in this paper will be annualized and converted into yearly return rate. Annualized return rate can be obtained through:

$$
r_{p_{-} y}=r_{p_{-} K} \times(12 / K)
$$

\section{Empirical Facts of Lagged ES and WRSS Testing Results}

\section{Hypothesis}

It can be noted from the literature review hereinbefore that most researches conducted by foreign scholars support the existence of short-term contrarian effect. Given the fact that the futures market in China is less mature than the ones in Europe and the US, timely and effective market information is hardly available to Chinese investors. As a result, high sentiment will occur in the short term, which aggravates market over-reaction. Therefore, this paper presents the first assumption as follows:

$\mathrm{H}_{1}$ : Contrarian phenomenon exits in Chinese futures market in the short term and contrarian strategy can produce significant positive excess return.

With regard to investors, most participants in Chinese futures market are medium and small investors. On one hand, without thorough knowledge of the market, these investors are insensitive to market information and are prone to under-reaction. On the other hand, without sufficient knowledge of investment, investors tend to be subject to non-rational factors. Initially when market information occurs, conservatism is more likely to dominate the market. Though reaction is gradually made to that information later, participants are often affected by herding effect, which boosts the market price in a blind manner and leads to the contrarian phenomenon in the long term. Hence the second assumption is presented as follows:

$\mathrm{HO}_{2}$ : Contrarian phenomenon in Chinese futures market results from delayed over-reaction. The return produced from the contrarian strategy is manifested by middle-term momentum and long-term contrarian. 


\section{Abnormal Returns of Chinese Futures Markets}

This paper adopts overlapping sampling for the purpose of avoiding small sample bias resulting from non-overlapping sampling. Sampling period herein lasts for 156 months from January 1999 to December 2011. This paper selects the return rate data of short-term weekly frequency and mid-and-long-term monthly frequency in order to test the effectiveness of momentum and contrarian strategies in Chinese futures market. Both the short-term and mid-and-long-term data samples share the same time span (January 1999 to December 2011), type of futures and contracts. A total of five types of futures, namely, aluminum, copper, and rubber traded in Shanghai futures exchange, hard winter wheat traded in Zhengzhou futures exchange, and soybean (Soybean No.2) traded in Dalian futures exchange, are selected to represent Chinese futures market. Upon processing, there are altogether 642 short-term weekly data and 156 mid-and-long term monthly data.

When studying the momentum and contrarian effects in Chinese futures market in the selected short-term weekly frequency and mid-and-long-term monthly frequency, the return rate is expressed as weekly return rate and monthly return rate respectively. With regard to the weekly frequency, logarithm variance of closing price from one Wednesday to the Wednesday $t$ week(s) later is used to calculate the return rate. With regard to mid-and-long term, the third Wednesday of each month is selected as exchange day.

Table 1 describes the basic statistical features of weekly and monthly return rate respectively. Statistical result shows that the expected values of the five commodity futures are all positive but insignificant. This indicates that simply buying and holding the futures will not produce significant excess return.

Table 1

Description of Returns on Futures Product

\begin{tabular}{lllllll}
\hline & & Copper & Aluminum & Natural rubber & Soybean & Hard wheat \\
\hline \multirow{2}{*}{ Weekly } & Mean & 0.0204 & 0.0340 & 0.0002 & 0.0004 & 0.0008 \\
& Sd & 1.6504 & 1.8891 & 0.0460 & 0.0393 & 0.1034 \\
\multirow{2}{*}{ Monthly } & Mean & 0.0082 & 0.0009 & 0.0069 & 0.0048 & 0.0021 \\
& Sd & 0.0831 & 0.0413 & 0.0896 & 0.0559 & 0.0477 \\
\hline
\end{tabular}

Results of Lagged ES Model

In this paper, ranking period $(J)$ and holding period $(K)$ are divided into short term (one, two, four, and eight weeks for both), middle term (one to nine months for ranking period; one to 12 months for holding period) and long term (18, 24, and 36 months for both). A one-week lag is introduced to the short term and one-month lag to the middle and long term. Then, the existence of excess return in the futures market is tested by adopting a momentum strategy (buying winners in holding period and selling losers in ranking period). If the numerical value is positive, it shows that momentum effect is present in the futures market; if the value is negative, then the contrarian strategy will yield positive excess return.

With regard to the short term (see Table 2), 10 of the 16 investment strategies yield relatively significant negative return, with significance level of above $5 \%$. The remaining six strategies also yield negative return, but less significant. The significant negative return (return reversal) produced by the short-term investment strategy mainly results from the significant return of the losers. Among them, strategy portfolio under $J=1$ and $K=8$ produces the lowest contrarian return, with a return rate of $0.26 \%$; strategy portfolio under $J=8$ and $K=$ 1 produces highest contrarian return, with a rate of $8.22 \%$. In addition, when ranking period is four and eight weeks, significant negative return will occur at holding period one, two, four, and eight weeks. As portfolio 
return grows with the increase of the holding period, the contrarian phenomenon gradually disappears and mean reversion emerges.

Table 2

Test of Short-term Momentum Strategy (Equally \& Lag)

\begin{tabular}{|c|c|c|c|c|c|}
\hline$J$ (Formation Period) & $K$ (Holding Period) & 1 & 2 & 4 & 8 \\
\hline & buy & $0.76 \%$ & $0.03 \%$ & $-0.58 \%$ & $0.16 \%$ \\
\hline \multirow[t]{3}{*}{1} & sell & $-1.11 \%$ & $-2.68 \% * * *$ & $-1.08 \% *$ & $-0.42 \%$ \\
\hline & buy-sell & $-0.35 \%$ & $-2.65 \%$ & $-1.66 \% *$ & $-0.26 \%$ \\
\hline & buy & $-2.39 \%$ & $-1.31 \%$ & $-0.84 \%$ & $0.08 \%$ \\
\hline \multirow[t]{3}{*}{2} & sell & $-3.20 \% * *$ & $-3.53 \% * * *$ & $-1.75 \% * * *$ & $-0.70 \% * *$ \\
\hline & buy-sell & $-5.59 \% *$ & $-4.84 \% * *$ & $-2.59 \% * *$ & $-0.62 \%$ \\
\hline & buy & $-2.88 \% *$ & $-1.55 \%$ & $-1.38 \% * *$ & $-0.12 \%$ \\
\hline \multirow[t]{3}{*}{4} & sell & $-2.90 \% * * *$ & $-4.08 \% * * *$ & $-1.79 \% * * *$ & $-1.35 \% * * *$ \\
\hline & buy-sell & $-5.78 \% * * *$ & $-5.63 \% * * *$ & $-3.17 \% * * *$ & $-1.47 \% * *$ \\
\hline & buy & $-2.87 \% *$ & $-2.27 \% * *$ & $-1.39 \% * *$ & $-0.10 \%$ \\
\hline \multirow[t]{2}{*}{8} & sell & $-5.35 \% *$ & $-2.80 \% * * *$ & $-1.91 \% * * *$ & $-1.07 \% * * *$ \\
\hline & buy-sell & $-8.22 \% * *$ & $-5.07 \% * * *$ & $-3.30 \% * * *$ & $-1.17 \% * *$ \\
\hline
\end{tabular}

Notes. $T$ statistic in parentheses; $* * * p<0.01$, ${ }^{* *} p<0.05$, and $* p<0.1$; and yield is the average return during holding period.

With regard to the middle term (Table 3), though both positive and negative return occur, the $t$-test of middle-term returns as a whole is insignificant at $5 \%$ or $10 \%$ level. This result indicates neither momentum nor contrarian effect is significant in the middle term.

With regard to the long term (Table 4), all zero-cost investment strategies yield significant negative return and contrarian effect exists in the long term. Among them, strategy portfolio under $J=36$ and $K=36$ produces the lowest contrarian return, with a rate of 5.18\%; portfolio under $J=24$ and $K=18$ produces a return of $24.14 \%$, which is the highest. In terms of formation, returns produced by contrarian strategy mainly result from returns of the losers. As the portfolio return rate grows gradually with the increase of holding period, the contrarian phenomenon gradually weakens and mean reversion emerges.

Table 3

Test of Middle-term Momentum Strategy (Equally \& Lag)

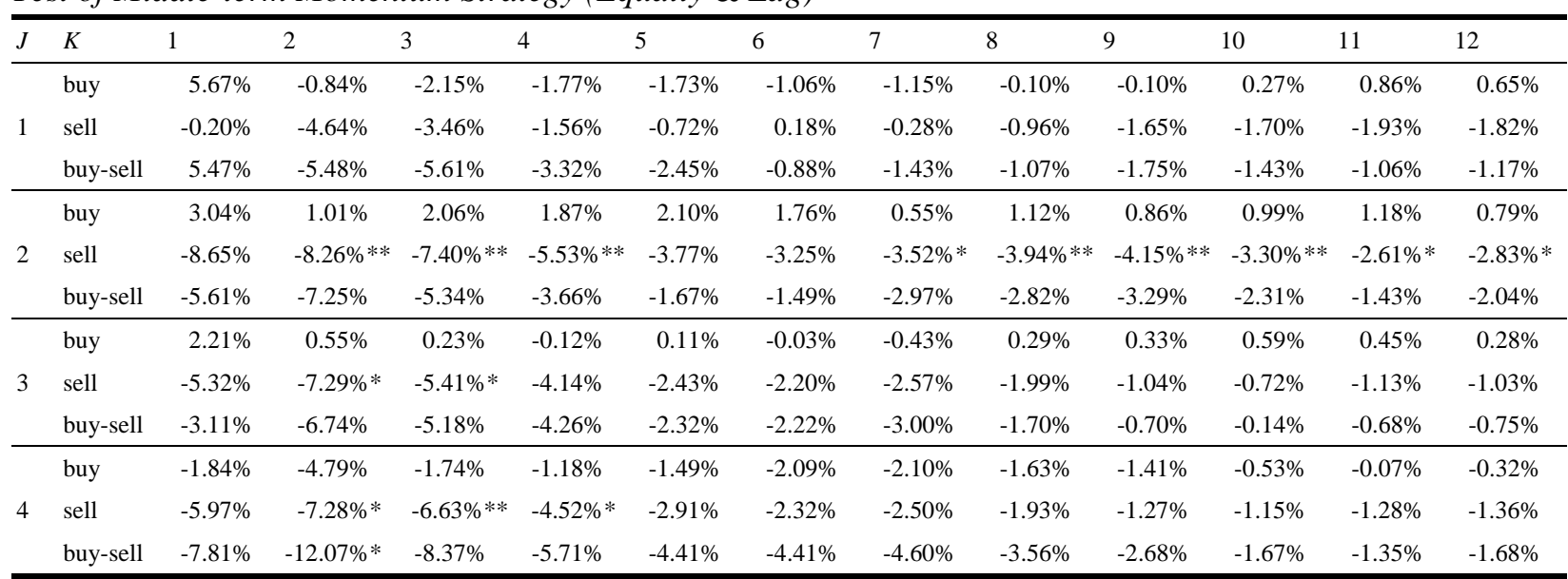


Table 3 to be continued

\begin{tabular}{lllllllllllllll}
\hline$J$ & $K$ & 1 & 2 & 3 & 4 & 5 & 6 & 7 & 8 & \multicolumn{3}{l}{10} & 11 & 12 \\
\hline \multirow{2}{*}{5} & buy & $-4.82 \%$ & $-2.79 \%$ & $-4.42 \%$ & $-4.61 \%$ & $-5.17 \% *$ & $-4.35 \% *$ & $-4.05 \% *$ & $-3.26 \% *$ & $-2.26 \%$ & $-1.84 \%$ & $-1.33 \%$ & $-1.56 \%$ \\
& sell & $-3.91 \%$ & $-5.95 \%$ & $-3.51 \%$ & $-2.21 \%$ & $-1.27 \%$ & $-1.74 \%$ & $-1.77 \%$ & $-0.73 \%$ & $-0.78 \%$ & $-0.65 \%$ & $-1.08 \%$ & $-0.37 \%$ \\
& buy-sell & $-8.73 \%$ & $-8.74 \%$ & $-7.92 \%$ & $-6.82 \%$ & $-6.44 \%$ & $-6.09 \% *$ & $-5.82 \% *$ & $-3.99 \%$ & $-3.04 \%$ & $-2.49 \%$ & $-2.41 \%$ & $-1.92 \%$ \\
\hline \multirow{2}{*}{6} & buy & $6.70 \%$ & $-0.23 \%$ & $-2.86 \%$ & $-2.05 \%$ & $-1.80 \%$ & $-0.42 \%$ & $-0.21 \%$ & $-0.16 \%$ & $-0.60 \%$ & $-0.24 \%$ & $0.03 \%$ & $-0.08 \%$ \\
& sell & $-5.03 \%$ & $-5.45 \%$ & $-2.73 \%$ & $-1.75 \%$ & $-0.81 \%$ & $-1.03 \%$ & $-1.78 \%$ & $-0.56 \%$ & $-0.57 \%$ & $-0.06 \%$ & $0.18 \%$ & $0.73 \%$ \\
& buy-sell & $1.67 \%$ & $-5.69 \%$ & $-5.59 \%$ & $-3.80 \%$ & $-2.61 \%$ & $-1.45 \%$ & $-1.99 \%$ & $-0.71 \%$ & $-1.17 \%$ & $-0.30 \%$ & $0.21 \%$ & $0.66 \%$ \\
\hline \multirow{2}{*}{7} & buy & $-2.00 \%$ & $-6.27 \%$ & $-6.60 \%$ & $-5.18 \%$ & $-3.59 \%$ & $-2.19 \%$ & $-1.95 \%$ & $-1.75 \%$ & $-2.57 \%$ & $-2.40 \%$ & $-1.71 \%$ & $-1.41 \%$ \\
& sell & $-6.54 \%$ & $-6.28 \% *$ & $-4.35 \%$ & $-2.55 \%$ & $-1.93 \%$ & $-1.37 \%$ & $-0.90 \%$ & $-0.40 \%$ & $0.13 \%$ & $0.76 \%$ & $1.08 \%$ & $1.09 \%$ \\
& buy-sell & $-8.53 \%$ & $-12.55 \% *$ & $-10.94 \% *$ & $-7.72 \%$ & $-5.52 \%$ & $-3.57 \%$ & $-2.85 \%$ & $-2.15 \%$ & $-2.43 \%$ & $-1.64 \%$ & $-0.63 \%$ & $-0.33 \%$ \\
\hline \multirow{2}{*}{8} & buy & $1.16 \%$ & $-2.28 \%$ & $-2.83 \%$ & $-2.22 \%$ & $-1.41 \%$ & $-1.07 \%$ & $-0.94 \%$ & $-1.30 \%$ & $-2.01 \%$ & $-2.08 \%$ & $-1.63 \%$ & $-0.88 \%$ \\
& sell & $-5.31 \%$ & $-6.79 \% *$ & $-5.88 \% *$ & $-2.59 \%$ & $-0.98 \%$ & $-0.95 \%$ & $-0.47 \%$ & $0.03 \%$ & $0.06 \%$ & $0.12 \%$ & $-0.29 \%$ & $-0.40 \%$ \\
& buy-sell & $-4.15 \%$ & $-9.07 \%$ & $-8.71 \%$ & $-4.82 \%$ & $-2.38 \%$ & $-2.02 \%$ & $-1.42 \%$ & $-1.27 \%$ & $-1.96 \%$ & $-1.96 \%$ & $-1.92 \%$ & $-1.28 \%$ \\
\hline \multirow{2}{*}{9} & buy & $-2.08 \%$ & $-5.35 \%$ & $-3.85 \%$ & $-2.51 \%$ & $-1.42 \%$ & $-1.52 \%$ & $-1.68 \%$ & $-1.86 \%$ & $-1.91 \%$ & $-1.93 \%$ & $-1.42 \%$ & $-0.85 \%$ \\
& sell & $-9.01 \% *$ & $-6.26 \%$ & $-3.73 \%$ & $-1.01 \%$ & $-0.88 \%$ & $-1.15 \%$ & $-0.82 \%$ & $-0.69 \%$ & $-0.49 \%$ & $-0.80 \%$ & $-0.72 \%$ & $-0.81 \%$ \\
& buy-sell & $-11.09 \%$ & $-11.62 \% *$ & $-7.57 \%$ & $-3.53 \%$ & $-2.30 \%$ & $-2.67 \%$ & $-2.50 \%$ & $-2.55 \%$ & $-2.40 \%$ & $-2.73 \%$ & $-2.14 \%$ & $-1.66 \%$ \\
\hline
\end{tabular}

Notes. J: Formation period and $K$ : Holding period; $T$ statistic in parentheses; $* * * p<0.01,{ }^{* *} p<0.05$, and $* p<0.1$; yield is the average return during holding period.

Table 4

Test of Long-term Momentum Strategy (Equally \& Lag)

\begin{tabular}{|c|c|c|c|c|}
\hline$J$ (Formation Period) & K (Holding Period) & 18 & 24 & 36 \\
\hline & buy & $-4.07 \%$ & $-2.81 \%$ & $0.05 \%$ \\
\hline \multirow[t]{3}{*}{18} & sell & $-16.83 \% * * *$ & $-12.27 \% * * *$ & $-12.34 \% * * *$ \\
\hline & buy-sell & $-20.89 \% * *$ & $-15.08 \% * * *$ & $-12.29 \% * * *$ \\
\hline & buy & $-6.36 \%$ & $-4.47 \%$ & $-1.53 \%$ \\
\hline \multirow[t]{3}{*}{24} & sell & $-17.78 \% * * *$ & $-19.61 \% * * *$ & $-8.87 \% * * *$ \\
\hline & buy-sell & $-24.14 \% * * *$ & $-24.08 \% * * *$ & $-10.40 \% * * *$ \\
\hline & buy & $-3.33 \%$ & $-3.72 \%$ & $-1.61 \%$ \\
\hline \multirow[t]{2}{*}{36} & sell & $-12.18 \% * * *$ & $-9.09 \% * * *$ & $-3.57 \%$ \\
\hline & buy-sell & $-15.51 \% * *$ & $-12.81 \% * *$ & $-5.18 \% * * *$ \\
\hline
\end{tabular}

Notes. $T$ statistic in parentheses; $* * * p<0.01$, ${ }^{* *} p<0.05$, and $* p<0.1$; and yield is the average return during holding period.

\section{Results of Lagged WRSS Model}

By adopting WRSS, this paper gives higher weight to stock that performed better in the past. Under the weighted method and according to the empirical results of short, middle and long term, WRSS strategy produces generally the same result with that of the equally weighted strategy, except that its short-term return is slightly lower and long-term result slightly higher.

From the above empirical test based on equally weighted and weighed method, it can be seen that: (1) There is an relatively significant contrarian effect in the short term in Chinese futures market, which verifies the assumption 1 presented herein above; (2) both momentum effect and contrarian effects are insignificant in the middle term, but contrarian effect in the long term is relatively significant, and contrarian return to some extent results from market over-reaction, these results contradict assumption 2 presented herein above; and (3) compared with WRSS, equally weighed method can lead to both of the above results. It finds that, in short-term 
and long-term contrarian effect, portfolio return rate gradually rises and contrarian effect gradually weakens with the increase of holding period, and then mean reversion occurs.

\section{Conclusions}

This paper explores the momentum and contrarian effect in Chinese futures market in the short, middle and long term respectively by adopting a most widely-used zero-cost investment strategy (buying winners and selling losers portfolio), which is subdivided into equally weighted and lag strategy as well as weighted and lag strategy, to test the weekly and monthly transaction data of major commodity futures traded in three Chinese futures exchanges from 1999 to 2011. This empirical study finds that in Chinese futures market, there exists a relatively significant contrarian effect in the short term, contrarian effect is also present in the long term, and contrarian return to some extent results from market over-reaction.

With regard to Chinese futures market, the contrarian effect emerging in the short term and long term mainly attributed to the following distinctive factors:

(1) Defective information transfer system. Owing to the low maturity of Chinese futures market, regulatory regime and micro-transaction mechanism also remain immature. There is a gap between Chinese futures market and the developed ones abroad, in terms of information release and transfer system as well as transparency assurance mechanism. There remain weaknesses in Chinese futures market, such as the incorrect information, delayed release, inadequate or false disclosure, and etc.. Hence, most investors have little access to the market information they deserve. A small number of investors manage to obtain internal information through various means, which results in the unequal distribution of information. It needs to be pointed out that defective information transfer system doesn't mean slow information transfer. The former may lead to information distortion, causing greater noise in the information; the latter is responsible for under-reaction in the market. It can be indicated from the above empirical study that Chinese futures market features over-reaction.

(2) Mean reversion in the contrarian effect. As indicated in the empirical study, Chinese futures market tends to have contrarian effect in the long term, and this trend can be explained by mean reversion. Futures market has a function of price discovery. No matter how long the rising or falling trend lasts, the market will eventually return to its long-term performance track. According to this theory, there will be negative self-correlation in asset return in the long term. This means that contrarian phenomenon is present in the market and contrarian strategy can produce excess return.

(3) Immaturity of investors' mentality. Ninety-five percent of investors in Chinese futures market are medium and small investors, while only $5 \%$ of them are institutional investors. On one hand, compared with their counterparts in the developed futures markets abroad, China's futures investors feature immature mentality and limited analysis ability and are prone to cognitive bias. Furthermore, in China's capital market, information cannot fully, truly, and effectively reflect the real fundamentals of assets. In addition, investors' judgments will aggravate information distortion. All these will cause blindness in market transaction. On the other hand, given the large proportion of medium and small investors, the herding effect caused by them will lead to positive feedback, which further intensifies the market blindness. As market tends to be driven by rumors and investors' mentality rather than by information, it is prone to fluctuations. Besides, due to the small number of institutional investors, it is difficult to form competition. Without such competition, capital from institutional investors may end up manipulating the price, causing loss to medium and small investors. This 
also contributes to market over-reaction.

Although transactions after 2011 are not included in this empirical study, futures markets were reviving in China after 2011. With exponential growth in market size and significant power of influence, China's futures market has made a number of breakthroughs in past three years with regard to the number of products available for trading, industry structure, business scope, and regulatory philosophy. Both the OTC market and the exchange-traded market will have great potential to thrive. Thus, a worthwhile direction for future research would be a follow-up examination on changes of the momentum and contrarian effects in Chinese futures markets after 2011.

\section{Reference}

De Bondt, W., \& Thaler, R. (1985). Does the stock market overreact? Journal of Finance, 40(3), 793-805.

Fama, E. F. (1998). Market efficiency, long-term returns, and behavioral finance. Journal of Financial Economics, 49(3), 283-306.

Fama, E. F., \& French, K. R. (1992). The cross-section of expected stock returns. Journal of Finance, 47(2), 427-465.

Jegadeesh, N., \& Titman, S. (1993). Returns to buying winners and selling losers: Implications for stock market efficiency. Journal of Finance, 48(1), 65-91.

Jegadeesh, N., \& Titman, S. (1995). Short-horizon return reversals and the bid-ask spread. Journal of Financial Intermediation, 4(2), 116-132

Jegadeesh, N., \& Titman, S. (2001). Profitability of momentum strategies: An evaluation of alternative explanations. Journal of Finance, 56(2), 699-720.

Joëlle, M., \& Georgios, R. (2007). Momentum strategies in commodity futures markets. Journal of Banking and Finance, 31(6), $1863-1886$.

Lo, A. W., \& Mackinlay, A. C. (1990). Data-snooping biases in tests of financial asset pricing models. Review of Financial Studies, 3(3), 431-468.

Pilar, C. Luis, M., \& Rafael, S. (2005). The profitability of momentum strategies using stock futures contracts in small markets. Applied Financial Economics Letters, 2(3), 223-229.

Pirrong, C. (2005). Momentum in futures markets. Retrieved from http://dx.doi.org/10.2139/ssrn.671841

Shen, Q., Szakamary, A. C., \& Sharma, S C. (2007). An examination of momentum strategies in commodity futures markets. The Journal of Futures Markets, 27(3), 227-256.

Wang, C. Y. (2004). Do futures markets overreact? Retrieved from http://www.ccfr.org.cn/cicf2005/paper/20050108165222.PDF 